\title{
LAS ARTES EN LA OBRA DE FRAY DIEGO TADEO GONZÁLEZ
}

La relación entre las distintas modalidades artísticas enriquece podero samente el conocimiento de los sucesivos períodos culturales, a la vez que va abriendo nuevas perspectivas a la hora de interpretar un mismo fenómeno cultural. Pensemos, por ejemplo, en una dirección artística como la «rococó» y su plasmación en la poesía, la arquitectura, la escultura o la pintura; o lo que es lo mismo, evoquemos algunos poemas de Meléndez Valdés, de Cadalso, por citar algunos nombres de entre los muchos que cultivaron Ia modalidad anacreóntica; ciertas estancias del palacio de Schönbrunn en Viena; lienzos de Watteau reflejando las "fêtes galantes"; y un sinnúmero de porcelanas de la época que tienen la fragilidad, suavidad de colorido y exquisitez de una figurita de (biscuit). Todos ellos tienen en común varios aspectos e ilustran a la perfección lo que una modalidad artística impregna a las diversas bellas artes ${ }^{1}$. La crítica, estudiando y analizando cada una de estas modalidades desde sus distintos campos, ayuda a que las asociaciones entre unas y otras sean cada vez más fecundas.

Sucede, en ocasiones, que son los propios artistas los que nos dan sus impresiones en materia de arte, ya sea para explicar los principios que rigen su creación o para expresar su actitud ante las artes en general. Estos juicios pueden ser muy valiosos y sugerentes porque nos permiten conocer el gusto de la época desde un punto de vista personal, que puede coincidir o no con la preceptiva estética de su, siglo. Dentro de este planteamiento

1 Sobre este campo de la Literakura y el arte nos han sido de utilidad, entre otros, los estudios de: Hauser, A., Historia social de la Literatura y el Arte, Madrid, Guadarrama, 3 vols., 1957: Orozco, E., Mística, Plástica y Barroco, Madrid, Cupsa, 1977; Helman, E., Jovellanos y Goya, Madrid, Taurus, 1970; Moreno Báez, E., Nosotros y nuestros clásicos, Madrid, Gredos, 1961. 
creemos que se encuentra el poeta Diego Tadeo González (1732-1794), fraile agustino, que cultivand exclusivamente la poesía, y a través de ella, nos dejó algunas opiniones sobre pintura, escultura y arquitectura

En el año 1781 aparece publicada en Madrid una oda de fray Diego titulada $A$ las Nobles Artes ${ }^{2}$. Fue una de las pocas composiciones que se editaron en vida del poeta, enemigo de que sus obras vieran la luz pública por considerar sus méritos escasos. Estando al borde de la muerte pidió a su amigo Juan Fernández de Rojas que quemara su obra.

Esta oda pertenece a un segundo período en la producción del poeta, en el que abandona la poesía ligera, de temática amorosa, encuadrada en un ambiente idílico o pastoril, para dedicarse al cultivo de una poesía más seria y elevada. Este giro evolutivo se opera hacia el año 1776 , cuando los consejos de Jovellanos ejercen una marcada influencia sobre fray Diego ${ }^{3}$.

Debió de ser compuesta a partir del mes de abril de 1779, cuando fray Diego deja Salamanca para trasladarse a Madrid, como Secretario de Provincia. Fue impresa el 14 de julio de 1781. El poeta se da perfecta cuenta por estas fechas de que su talento no era el más adecuado para este tipo de composiciones:

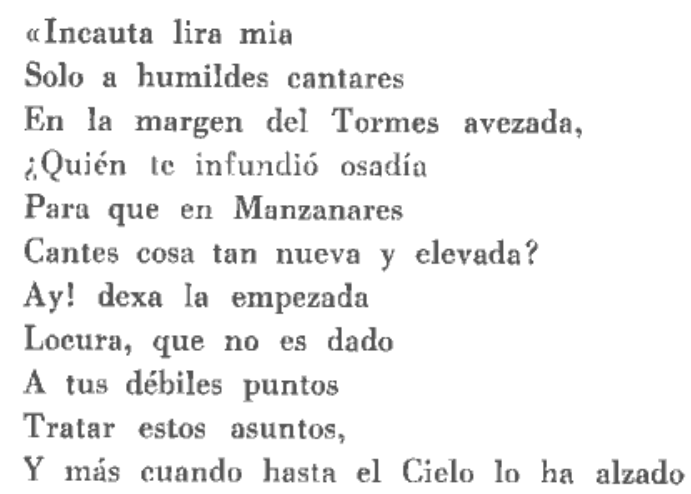

2 Apareció incluida en el impreso Distribución de los premios concedidos por el Rey nuestro Señor ... hecha en la Real Academia de S. Fernando en la Junta pública de 14 de julio de 1781. He tomado esta información de Santiago Vela, G., "González (Fr. Diego)" en Ensayo de una biblioteca Ibero-Americana de la Orden de San Agustín, vol. III, Madrid, 1917, p. 158.

3 Vallejo González, I., "Fray Diego Tadeo González», en Archivo Agustiniano, LXI (1977), pp. 70 y sigs. 
Con verso más divino

De otras liras el canto peregrino" ${ }^{4}$

¡Lástima que siguiera este camino dificultoso y abandonara aquel otro más sencillo y natural en él!

Hay en sus versos una clara condena del siglo anterior, al que califica de (corrompido», porque piensa que (el honor de tus Artes ha manchado»; a su vez, deposita una gran confianza en el triunfo del nuevo gusto, que sustituirá «el ya pasado desatino». Es decir, rechaza lo anterior y acepta la nueva estética.

Después de esta consideración inicial, singulariza y elogia las propiedades de la Pintura, de la Escultura y de la Arquitectura.

De la pintura destaca las siguientes cualidades: capacidad para sublimar la realidad, enseñar y deleitar, y recrear artística y personalmente la verdad imitada:

\author{
«En superficie lisa \\ Sin que causen aumento \\ Colocar valles, montes, selvas, ríos \\ A distancia precisa; \\ Acción sin movimiento, \\ Fondos, lejos, alturas y vacios; \\ La mar de sus navíos \\ Separar, y la tierra \\ Del globo refulgente \\ Y sombra que la luz nunca destierra; \\ Jamás logró natura \\ Solo es don tuyo celestial Pintura! $)^{5}$
}

4 Poesias del M. F. Diego González, Madrid, 1796, p. 32.

5 Hemos podido ver una versión manuscrita de esta obra en el convento de los PP. Agustinos de Valladolid, cataloggada en el Arotivo Agustiniano como legajo 4964. Se encuentra con numerosas correcciones y tachadarns, e intitulado. En la segunda estrofa de las dos dedicadas a la Pintura hemos encontrado incluido un verso más que no aparece en la primera edición de 1796:

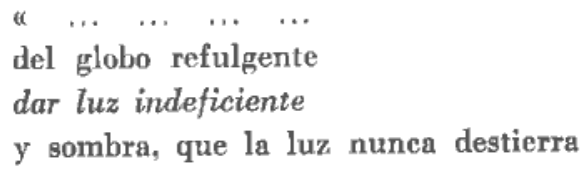


La Escultura consigue inmortalizar a los grandes hombres después de muertos, e incluso vivificar asuntos mitológicos, como sucedió con Dafne y Anaxárete. Es decir, considera que el artista puede crear imitando la realidad, pero también dando forma a lo fabuloso.

A la escultura le otorga un papel importante en la organización social: viviendas, regios palacios, templos y ciudades. Consideramos que le atribuye una mayor practicidad.

Todas estas reflexiones en torno a las artes están plenamente de acuerdo con la ideología de su siglo. Algunas se basan en preceptos fundamentales de la estética clásica. Sin embargo, en fray Diego apreciamos una fuerte carga religiosa que no se puede sustraer a sus opiniones artísticas y que aflora constantemente. Así lo vemos ya en los primeros versos:

«Levanta ya del suelo

El rostro lagrimoso

Virtud, hija del Cielo, don divino».

Y continúan adjetivos y sustantivos como «celestial», «divina», (cielo», etc., abundando en esta idea. A veces es toda una estancia:

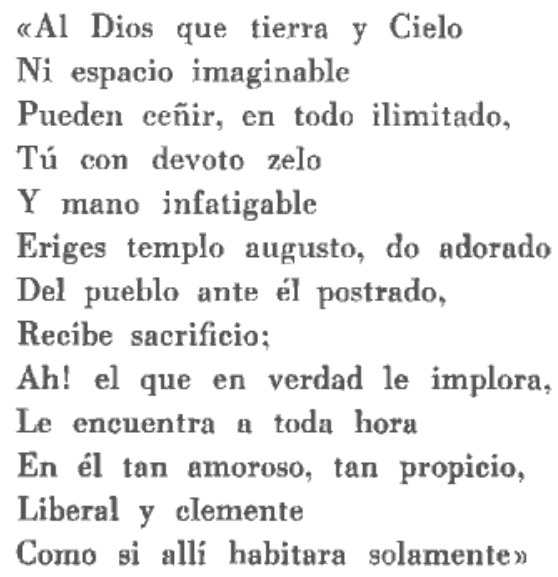

Esta actitud en nuestro poeta no sólo se justifica en razón de que sea agustino, teólogo y persona muy estimada dentro de su profesión religiosa, sino también por la tendencia que tanto en su siglo como en la antigüedad clásica había en considerar la inspiración del artista como de origen divino. Fray Diego sería un eslabón más en la cadena secular que sustituyera la ideología pagana por la cristiana.

- "Eriges Templo augusto do es adorado» por "eriges templo augusto, do adorado».

- «de otros Cisnes el canto peregrino» por «de otras liras el canto peregrinow. 
De todas las artes, fue la Pintura a la que fray Diego dedicó mayor atención. En la primera edición de sus poesías, en 1796, encontramos dos poemas de interés para el tema que nos ocupa. Uno de ellos es la octava titulada $A$ una pintura confusa de la gloria:

«Una rara visión que representa

Un conjunto de varias confusiones

En color de azafrán y de pimienta,

Donde a costa de muchas atenciones

Sólo nota la vista más atenta

Manos, patas, cabezas, pies y alones,

¿Por qué motivo se ha de llamar gloria?

¿No era mejor llamarla pepitoria?

No sabemos a qué cuadro concreto se refiere ni quién pudo ser ssu autor. El poeta mantiene al respecto la discreción que debió ser natural en él, máxime cuando se trataba de emitir un juicio negativo. Sin embargo, su admiración por el arte pictórico se resiste a aceptar una obra tan poco afortunada. Reprueba preferentemente la falta de claridad en la composición; el desorden; esas manos, patas, cabezas, en fin, partes perdidas que corresponden lógicamente a un todo. Esto responde al gusto neoclásico, que prefiere la claridad y el orden frente a lo oscuro y desordenado.

Tampoco son del agrado del poeta los colores de azafrán y pimienta como los más adecuados para el tema. Los dos versos finales sintetizan y condensan plenamente su actitud crítica. Este matiz satírico-burlesco tiene algo de eco lejano de los grandes satíricos del s. XVII, aunque la ideología que alienta y los aspectos que censura son propios de la mentalidad de la época. Precisamente censura la falta de unas normas aceptadas como reglas dentro del arte.

El otro poema incluido en la edición de 1796 es una décima que lleva por título A la noche pintada por J. Vernet. A diferencia del anterior, conocemos el autor y título del cuadro.

Claude Joseph, o simplemente Joseph, Vernet fue un pintor francés, nacido en Avignon en 1714 y fallecido en París en $1789^{6}$. A los veinte años fue a Italia y tras una estancia bastante prolongada y provechosa volvió definitivamente a su país. Perteneció a las academias de San Lucas de

6 Gay, C., El siglo XVIII, Madrid, Aguilar, 1969, vol. 14, p. 199. 
Roma y a la de París. Dentro de su obra total se pueden destacar las Es. cenas de la vida romana, una serie de cuadros sobre los puertos de Francia y un buen número de paisajes y marinas, en los que la crítica le considera un especialista. De él se ha dicho: «La serenidad, completamente clásica, de sus paisajes italianos envolvería, durante algunos años, las marinas y los "puertos de Francia» que ejecutó por encargo del rey y que el hábil topógrafo animaba con multitud de personajes. Pero pronto la sombra invadió sus paisajes marinos, para que en ellos sólo adquiriesen realce la luz del claro de luna o los resplandores de la tempestad. Vernet dramatizó la naturaleza, en busca de contrastes cada vez más sobrecogedores) ?

Diderot admiró entusiasmado el arte de Vernet: «Los mares se encrespan o se tranquilizan, a su gusto; el cielo se obscurece, el rayo se enciende, el trueno brama, la tempestad se desencadena; los barcos se juntan; oímos el ruido de las alas, los gritos de los que perecen; vemos ... vemos todo lo que él quieres ${ }^{8}$.

La pintura francesa del siglo XVIII contó con una serie de brillantes representantes de las distintas tendencias de la época, como Watteau, Boucher, Chardin, La Tour, Grenze, y otros. Los paisajes de Vernet y de Hubert Robert representarían hasta cierto punto una visión romántica de la naturaleza. Lo verdaderamente sorprendente es que un poeta como fray Diego, que parece profeșar una estética neoclásica y que no tiene el menor atisbo prerromántico en su obra, tuviera estas predilecciones pictóricas.

Por el título de la décima, pensamos que el cuadro al que se refiere sea el conservado en el museo del Louvre, titulado Marine, la Nuit ou le Clair de lune o algún otro de composición similar.

Fray Diego no se detiene a describirlo, sino que hace una reflexión elogiando la capacidad de abstracción del pintor para poder reproducir tan fielmente la noche en el lienzo. En los cuatro primeros versos plantea el tema:

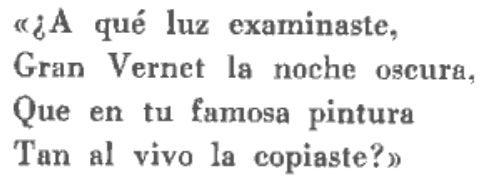

Los adjetivos "gran» y "famoso» manifiestan a los claras su admiración y consideración por el pintor. En los versos restantes utiliza una técnica

7 Ibid., pp. 32 y 33.

8 Ibid,, p. 100. Otro testimonio de admiración en la p. 98. 
discursiva sirviéndose de contrastes, que copera más aún a realzar la perfecta consecución del tema pintado:

$$
\begin{aligned}
& \text { «Si de noche la pintaste, } \\
& \text { ¿Qué luz tu pincel guió? } \\
& \text { Si de día, no se yo } \\
& \text { Cómo tanta obscuridad, } \\
& \text { Juzgándola realidad, } \\
& \text { Su luz no la disipó». }
\end{aligned}
$$

La última composición a la que nos vamos a referir no apareció incluida en la primera edición de las obras de fray Diego ${ }^{9}$. Es la décima titulada Pintura deseada y está dedicada a Mirta. Nombre femenino que no es accidental o casual en su obra, ya que Mirta y Melisa fueron las musas constantes de sus poemas amorosos. Mirta fue precisamente la protagonista de la obra más conocida del autor, El murciélago alevoso.

Conocemos la identidad real de Mirta. Se llamaba María del Carmen González Llorente y vivía en Cádiz ${ }^{10}$. Fray Diego debió de conocerla con motivo de un viaje que realizó por Andalucía en el año 1774. El agustino se sintió atraído por las cualidades morales de esta mujer; al menos eso parece desprenderse de los comentarios que hacía a sus amigos: Siento que Vm. no viese en Cádiz a la fiel Mirta. Ciertamente no hubiera Vm. visto una Venus, sin embargo de que nada tiene de despreciable su figura; pero al menos hallaría un alma digna de ser amada, encerrada en un cuerpo lleno de modestia y compostura; prendas que le granjearon todo el amor de Delio, quien aborrece toda mujer que no se recomienda a sus ojos por medio de tales prendas " ${ }^{11}$.

En la décima reitera este gran afecto y admiración realmente sentidos. Deja volar la imaginación para así idealizar más la figura de la mujer amada. El sentimiento se sobrepone a la razón y emerge el deseo irreal:

«Si la efigie verdadera

De Mirta se ha de formar,

9 Cueto, L. A., Poetas líricos del s. XVIII, en Biblioteca de Autores Españoles, vol. LXI, Madrid, 1869, p. 201. Aqui está incluido este poema. No hemos comprohado si acaso to ha recogido en alguna edición anterior.

10 Santiago Vela, G, ob. eit., pp. 148 y 149 , en nota. En esta última recoge el comentario textual de Adolfo de Castro que refiere quién fue Mirta

11 Cueto, L. A., ob. cit., p. CIX, nota 2. 
Debe el cielo aparejar

Todo el lienzo de su esfera,

Es preciso que el sol diera

Sus rayos para pinceles,

Color sus virtudes fieles,

$\mathrm{Su}$ grande prudencia el tiento,

Digna idea su talento

La mano el supremo Apeles».

En estos versos reencontramos la sencillez, entusiasmo y naturalidad de los poemas de su primera época. La voz del hombre que vibra ante la belleza femenina y que al contemplarla exclama:

«Cuánto aventaja ol arte

La fiel naturaleza)

(A Lisi malagueña)

Los poemas seleccionados nos han permitido conocer la actitud de fray Diego hacia las artes. Notemos que únicamente se ocupa de las artes Ilamadas "visuales», sin hacer ninguna alusión al resto ${ }^{12}$. Quizá la selección se deba a que la oda "A las Nobles Artes» la compuso con motivo de la distribución de premios concedidos por el rey en la Academia de San Fernando, y por este motivo limitara sus comentarios a las artes que tenían significado especial en aquella circunstancia.

La Pintura ejerció en él un gran atractivo, posiblemente porque su gusto $\mathrm{y}$ sensibilidad encontraron en esta modalidad artística una mayor afinidad con là que él desarrolló. Me atrevería a decir que, en términos generales la poesía de Fray Diego es preferentemente descriptiva y la asociación con la pintura emana con facilidad:

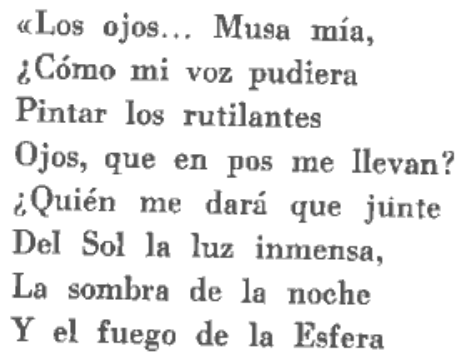

12 Beardsley, M. C. y Hospers, J., Estética, Historia y Fundamentos, Madrid, Cátedra, 1976, pp. 115.116. 
Para pintar sus brillos,

Su gracia y su viveza?

(En los días de Lisi)

Su preceptiva estética se podría sintetizar diciendo que responde al estilo de la segunda mitad del s. XVIII, con un rechazo de lo anterior y vuelta a la normativa clásica: imitación de la naturaleza; la doble finalidad del arte de utilidad y deleite ${ }^{13}$; armonía y orden frente a lo disarmónico y desordenado; así como una especie de neoplatonismo cristianizado en la concepción de la belleza artística.

A todas estas ideas fundamentales habría que añadir, de acuerdo con la actitud racionalista del periodo, la valoración específica que da sobre el talento del artista y el poder del arte para sublimar la realidad.

Sin embargo, estas opiniones no nos parecen acotadas de modo absoluto por el artista. Hay pequeñas filtraciones que reflejan una actitud distinta y a veces paradójica. Para valorar el talento creador elige a un pintor como Vernet, que tiene bastantes rasgos prerrománticos. ¿No encajaría mejor un pintor estrictamente neoclásico? Cuando se refiere a recuerdos o vivencias personales, la fantasía desborda la razón, como ocurre en Pintura deseada. Otras veces las visiones reales le parecen irreproducibles artísticamente. De aquí deduce la superioridad de la naturaleza sobre el arte, y en otro momento, nos dice que el arte es capaz de sublimar la realidad.

En nuestra opinión, la postura de fray Diego frente al arte en general no fue monocorde, como tampoco lo fue en materia estrictamente literaria.

Irene VALLEJO GonzAlez

13 García Berrio, A., Formación de la Teoría Literaria moderna. La tópica horaciana en Europa, Madrid, Cupsa, 1977. 